\title{
Medusa: How the Literary Muse Became an Emblem for
}

\section{Feminism}

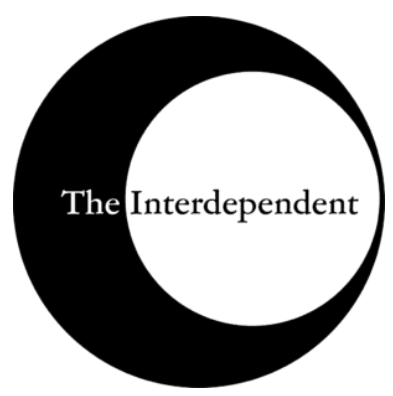

Beverly Tan | bwt228@,nyu.edu

B.A. Global Liberal Studies, $2020 \mid$ New York University, New York

M.A. Candidate | Teachers College, Columbia University, New York

https://doi.org/10.33682/nzgc-1pxs

\begin{abstract}
From Ancient Greece to Hollywood, Medusa has been a global narrative. This article explores poetry and storytelling through the historical and literary legacy of Medusa; it argues for her importance in feminist history and her continued relevance in our post-MeToo world. While a seemingly straightforward tale, Medusa's story explores female dynamics, feminist power against patriarchal forces, and the ultimate defense against the male gaze. This paper showcases a historical account of the handling of the Medusa myth which proves that the rewriting and reclaiming of the myth by women parallels, if not contributes to the success of female empowerment. Accompanying this paper is a poetry collection that explores varying perspectives within rape culture, including the sexualization of Billie Eilish.
\end{abstract}

\section{Keywords}

Medusa; Ovid; Billie Eilish; MeToo Movement; Feminism; Rape Culture; Female Gaze; Male Gaze; Aphrodite; Athena; Perseus. 


\section{Introduction, Medusa: Gorgon. Snakes for hair. Turns men into stone. Villain.}

\section{Murdered.}

Medusa is most well known for her death. Nevertheless, a story lies beyond her patriarchal-imposed villainy that starts before she turned into the snake-haired monster that we know of today. While a seemingly straightforward tale, Medusa's story explores female dynamics, female power against patriarchal forces, and the ultimate defense against the male gaze.

Medusa was the emblem of female power back in Ancient Greece and a symbol of both protection and aggression. Historically, Medusa has been used to serve different political agendas, and perspectives on her have changed dramatically. Now, she is a pop culture icon as the logo for the leading fashion brand Versace, and a reoccurring sex symbol in contemporary films. From protector to villain and the nuances that lie in between, Medusa has a lot of significance concerning female sexuality and power.

David Gurham expands on Ellison and Munro’s “Turning Mirrors into Windows?” to say that "when people look at the issue of rape, what they 'see' is not a clear view of the relevant facts and evidence, but rather a montage of images composed of their own deeply ingrained prejudices, stereotypes, and false beliefs reflected back to them." 52 Thus, a victim's story told through the perspective of its conqueror — as was in Ovid's Medusa myth—must be explored through the protagonist's eyes and that story should be foregrounded and given validity.

Additionally, an exploration and analysis of Medusa is the perfect gateway into the contemporary discourse of rape culture, the rising trend of sexual assault cases coming to light,

\footnotetext{
52 David Gurnham, "Ched Evans, Rape Myths and Medusa's Gaze: A Story of Mirrors and Windows," International Journal of Law in Context 14, no. 3 (September 2018): 458, https://doi.org/10.1017/S1744552318000010.
} 
and the vilifying of sexual assault victims. In her "Medusa and the Female Gaze," Susan Bowers summarizes that "Medusa's mythical image has functioned like a magnifying mirror to reflect and focus Western thought as it relates to women, including how women think about themselves." 53

\section{The Myth}

The most common thread in the Medusa myth, as seen in oral traditions and visual representations, is that the beautiful Medusa was the only mortal human ${ }^{54}$ of the three Gorgon sisters. One day, her long golden hair caught the eye of Poseidon who later raped her in the temple of Athena. In anger, Athena turned Medusa's luxurious hair into hissing snakes, and anyone who looked her in the eyes turned to stone. ${ }^{55}$

Perseus, son of Zeus, took it upon himself to slay Medusa. The gods instructed him not to look directly into Medusa's eyes, and Athena, his half-sister, even gave him her mirrored shield to use. Perseus later used the reflection in the shield as a pivotal strategy in killing Medusa and exploited her decapitated head to kill his enemies when brandishing it. Athena also used the symbol of Medusa's visage as a way to petrify her enemies by putting it on her aegis, or shield. Medusa, while a symbol of female rage, villainy, and something that incites fear in enemies, also became a symbol of protection. ${ }^{56}$

\footnotetext{
${ }^{53}$ Susan R. Bowers, "Medusa and the Female Gaze," NWSA Journal 2, no. 2 (Spring 1990): 217-35.

${ }^{54}$ Silverman cites Medusa as a human while other accounts from different sources differ. Across the board, Medusa is often labeled as the only mortal of the three gorgon sisters and described to look like a female woman with snakes for hair. Gorgons are Ancient Greek "monster figures." This paper assumes Medusa at least took on the form of a female woman but was not necessarily an actual human. Regardless of her canonical humanity, she represents women.

${ }^{55}$ Doris K. Silverman, "Medusa: Sexuality, Power, Mastery, and Some Psychoanalytic Observations," Studies in Gender and Sexuality 17, no.2 (2016): 116, http://dx.doi.org/10.1080/15240657.2016.1172926.

${ }^{56}$ Ibid.
} 
A close reading of Anthony Kline's translation of Ovid's Metamorphoses ${ }^{57}$ shows Athena being present for the rape and choosing to look away. This important overlooked moment makes it hard to accept the story as it is usually told, that is, that Athena transformed Medusa because she wanted to punish Medusa for despoiling her temple. According to Ovid, "Jupiter's daughter [Athena] turned away, and hid her chaste eyes behind her aegis." choice to hide away chaste (virginal, "innocent") eyes after witnessing someone getting raped arguably shows guilt and shame. One interpretation holds that because Medusa desecrated the temple of the virginal goddess Athena, Athena decided to punish Medusa by transforming her into a demon - the snakes, the power to turn people to stone, the fear she invokes - and rightly so, as Ovid continues, "So that it might not go unpunished, she changed the Gorgon's hair to foul snakes." 59 The reason for the transformation was punishment. Punishment for whom?

To give someone the power to terrify her enemies and numb them with fear is a gift. To iconicize others by brandishing them as part of your own brand is an honor. Another interpretation takes the stance that Athena was empowering Medusa, and the punishment Athena bestowed was on Poseidon and what he represented - the man, the rapist, the patriarchal oppressor. The fact that the most common retelling of the Medusa myth included the punishment of Medusa added to the subconscious or conscious demonizing of Medusa that was consistent with a patriarchal narrative. Perseus got to be the hero of this story. This perspective then influenced visual representations and contemporary beliefs and stereotypes surrounding Medusa,

\footnotetext{
${ }^{57}$ Kline's Metamorphoses is considered an authoritative and reliable translation. For the purpose of this paper, all future references to Ovid's narrative will come from Kline.

${ }^{58}$ Ovid, Metamorphoses, trans. A.S. Kline (The Ovid Collection at the University of Virginia Library, 2000) Bk 4, 801, https://ovid.lib.virginia.edu/trans/Metamorph4.htm\#478205208.

${ }^{59}$ Ovid, Metamorphoses, Bk 4, 802.
} 
which then shaped her identity and the "truth" about women, which more often than not was negative in the eyes of a patriarchal society.

\section{Decapitation, Petrification, and the Female Gaze}

Alongside Medusa's ability to turn men into stone, her decapitation has also been iconic for centuries. Freud believed that Medusa's decapitation "inflames the fear of castration." 60 Freud famously identified this childhood castration anxiety - "that is, the guilty fear that one's mortal and sexual transgressions might be punished by castration at the hands of paternal authority — as the drive of male moral and sexual development." 61 This fear propelled male audiences to be satisfied only with Medusa being decapitated, because "without a head, [Medusa couldn't] threaten [...] the male spectator with her own subjectivity." ${ }^{2}$ Headless, a woman turns into an object that cannot look back, that cannot protect herself, and thus welcomes to be looked at with abandonment. "Her mutilated body is a symbol of how men have been able to deal with women by relegating them to visual objectivity." 63 This visual detachment was the foundation that would later lead Laura Mulvey to coin the term 'male gaze,' which highlights "what men find so fascinating about the image of the female body $[\ldots]$ is that it represents a distant but crucial echo of that childhood fear [of castration]." 64

In his 1972 Ways of Seeing, John Berger emphasized European nude paintings to be very telling of centuries-old gender politics - that women are and have always been objectified and turned into spectacles for male viewing. These paintings frequently depicted naked women watching themselves — often in a mirror — or in sexually alluring "passive poses," aware they

\footnotetext{
${ }^{60}$ Silverman, "Medusa," 120.

${ }^{61}$ Gurnham, "Ched Evans," 461.

62 Bowers, "Medusa," 218.

${ }^{63}$ Ibid.

${ }^{64}$ Gurnham, "Ched Evans,” 461.
} 
were being spectated and accessed by the male viewer. The male handling of Medusa in literature, which this essay will discuss later, corroborates this cultural discourse. Berger wrote: Men act and women appear. Men look at women. Women watch themselves being looked at. This determines not only most relations between men and women but also the relation of women to themselves. The surveyor of women is herself male: the surveyed female. Thus she turns herself into an object of vision: a sight. ${ }^{65}$ Bowers argued that 'the history of women's images in Western culture is the history of an attempt to defuse the power of female eros." ${ }^{\prime 66}$ The male gaze has been so iconicized, Berger argued, that the woman that looks at herself has turned male and assumed the male gaze purely by its positioning. The Medusa myth resurrected the countermeasure to the perverse male gaze - the female gaze. It is a story that allowed women to reclaim their right to 'look' and not merely be looked at; it revealed the "powerful expression of female subjectivity and creativity" ${ }^{\prime 67}$ of such a gaze that has been oppressed for so long.

As Medusa's eyes see the world "in stone," in Stanford's poem "Medusa," her vision blurs, her fury and pain blind her, and it shows how "the female gaze can be deadened by oppression." ${ }^{\prime \prime 8}$ Medusa's story is a protest to the objectifying male gaze- "a feminist fantasy of furious and devastating rape revenge." ${ }^{\prime 9}$ The female gaze can challenge male dominance and switch the visual objectivity onto it. Bowers quoted Hazel Barnes, "it was not the horror of the object looked at which destroyed the victim but the fact that his eyes met those of Medusa looking at him;" a sentiment also expressed by Jean-Paul Sartre, "when another person looks at

\footnotetext{
65 Eamonn Carrabine, "Art and its Unruly Histories," in Routledge International Handbook of Visual Criminology, ed. Michelle Brown and Eamonn Carrabine (London: Taylor and Francis, 2017), cxli.

66 Bowers, "Medusa," 218.

67 Bowers, "Medusa," 219.

68 Ann Stanford, "Medusa," in In Mediterranean Air (New York: Viking Press, 1977), 42.

${ }^{69}$ Gurnham, "Ched Evans," 463.
} 
me, his look may make me feel that I am an object, a thing in the midst of a world of things. If I feel that my free subjectivity has been paralyzed, this is as if I had been turned to stone." Regardless of whether the gaze comes from a man or a woman, to look is "so disturbing because it constitutes judgement of the self from outside the self, judgement which can neither be controlled nor even known precisely." ${ }^{70}$ According to Barnes, such a look can categorize, identify, and judge; it threatens by ignoring free subjectivity, and it reveals physical and psychic vulnerability and fragility. ${ }^{71}$ The female gaze is the antidote combatting centuries of male violation. Such power is reflected not only in Medusa's ability to see men but also her ability to petrify them into stone. As Silverman put it:

When females are forcefully sexually assaulted and rapaciously used for male pleasure, it is a painful, terrorizing experience for them. The hurt and even humiliation can readily turn into wrath-filled vengeance. Satisfaction after such an onslaught might need to be an equally tormenting and violent experience for the offender. The deadly gaze turning men's hearts and minds to stone might satisfy a feminist fantasy. ${ }^{72}$

The only punishment deemed measurable and equally satiating a victim's wrath for revenge and equally as terrorizing would be to turn the assailant into stone.

\section{The Male Extortion of Medusa; Medusa in The Hands of Women}

Medusa has long been a muse for literature such as when she appeared in Dante's 1320 The Inferno, Percy Bysshe Shelley's poem “On the Medusa of Leonardo da Vinci in the

\footnotetext{
70 Bowers, “Medusa," 219.

71 Bowers, "Medusa," 219-220.

72 Silverman, "Medusa," 122. As you will notice, I rely heavily on the work of Silverman and Bowers, as have other scholars. They both are the foundation upon which so much is built and whose ideas are essential to my research. While my research might appear to heavily rely on the opinion of others, it is merely the program to the production that is my poetry collection on the very topic of Medusa and sexual assault.
} 
Florentine Gallery," and in Robert Lowell's poem "Near the Ocean."73 Male interpretations of Medusa often reflect their own fears and create a narrative for Medusa that protects male ego, virility, and domination. And there is often an undeniably sexual desire for Medusa and the female eros she represents, whether or not it hides a deeper-rooted antagonistic ambition for male domination.

Art historian Margaret Miles pointed out that fourteenth-century women's "sexuality and biological experience were pointedly rejected in favor of an idealized female image" but found "strong evidence that women at this time had considerable power in business, politics, and the church." ${ }^{74}$ Miles stated:

The spiritual autonomy of such women may have been deeply frightening to patrician men. The device of simultaneously distancing women and informing them of the role within the community that men preferred them to play made images of women attractive to men. For men, the totally visually and spiritualized — silent and bodiless — woman was manageable. ${ }^{75}$

The "manageable" silent and bodiless woman in contrast to the fourteenth-century powerful woman in business, politics, and the church, inscribed Medusa as the emblem of what men most feared: "sensual and powerful women."

\footnotetext{
73 Bowers, "Medusa," 224.

74 Bowers, "Medusa," 223.

75 Margaret R. Miles, Image as Insight: Visual Understanding in Western Christianity and Secular Culture (Boston: Beacon Press, 1985), 83-84.

76 Bowers, "Medusa," 224.
} 
Annis Pratt suggested that while male poets "remain separated from [Medusa], at a distance," "the poems by women move to an identification with Medusa."77 Female interpretations of Medusa often showcased Medusa's victimization and the violation of her erotic power.

Edith Sitwell’s “Medusa Love Song” and May Sarton’s “These Images Remain” both alluded to the connection between Medusa and Aphrodite. Sitwell depicted Medusa as an "unsuspecting Aphrodite figure, innocent of the ways of men."78 At the same time, Sarton described a transformation of Medusa and Aphrodite becoming one that was "the epitome of female beauty and eroticism" and inspired the poet to be "free and fertile."79 Sarton wrote:

Wrapped in the wind, the net of nerves undone,

So piercingly alive and beautiful.

Her breasts are eyes. She opens in the sun

And sees herself reflected in the sand

When the great wave has left her naked there,

And looks at her own feet and on her golden hair

As on some treasure given by the seas

To one who holds the earth between her knees. ${ }^{80}$

In Sarton's poem, Medusa's eyes turn into Aphrodite's breasts, ${ }^{81}$ insinuating that the power of Medusa's gaze and Aphrodite's sex appeal are one and the same, and that "what is about death in

\footnotetext{
77 Annis Pratt, "Aunt Jennifer's Tigers: Notes Toward a Preliterary History of Women's Archetypes," Feminist Studies 4, no. 1 (February 1978): 163-94. https://doi.org/10.2307/3177634.

78 Bowers, "Medusa," 228.

79 Bowers, "Medusa," 232.

${ }^{80}$ Ibid.

81 Ibid.
} 
the Greco-Roman myth transformed into that which is life-giving." 82 Unlike in Medusa's myth, where her image is reflected on Perseus' shield and thus deflected, the Medusa-inspired Aphrodite figure in Sarton's poem has her image reflected in the sand instead. Rather than enabling her murder, her reflection allows Aphrodite to marvel at herself as "a treasure given by the seas." 83 Sarton's empowering poem allows women to look at themselves in a way that does not have to be vain or lewd and allows them to recognize and harness an innate female power and view themselves as "one who holds the earth between her knees"- the source of life. Bowers added that Sarton's equation of Medusa and Aphrodite does three things:

First, she reminds us of Medusa, the beautiful young girl who was raped; second, she reunites Medusa's extraordinary power with Aphrodite's freshness and beauty; third and most importantly, she succeeds in radically revising a symbol of justification for female oppression, the fearsome seductress, into a femaleidentified, female-empowering figure. ${ }^{84}$

Medusa is the "passionate symbol for the woman poet's liberated self," 85 which allows women to own themselves and repossess parts of themselves that were once saved for, and at the mercy of, a society of men. Unlike the male poets' desires to control, gawk at, and kill Medusa within their poetry, and their battle with their ambivalent feelings towards her, Medusa in the hands of female poets is and has been a journey heavily focused on emotional healig, empowerment, and transformation.

\footnotetext{
${ }^{82}$ Ibid.

${ }^{83}$ Ibid.

${ }^{84}$ Bowers, "Medusa," 233.

${ }^{85}$ Ibid.
} 


\section{Medusa and the MeToo Movement}

Medusa's story parallels the MeToo narrative as both show how "sometimes truth does not lead to change. ${ }^{~} 86$ Whether it be Poseidon or Brett Kavanaugh or Donald Trump, history shows that pushback against sexual violence does little to disrupt "embedded power structures." ${ }^{17}$ In allowing a sexual assault assailant like Donald Trump—who admits to kissing and assaulting women without consent ${ }^{88}$ - to become President, we as a society communicate that we can "proceed largely undaunted," distribute "punishment with the utmost inequality," and collude with those who cynically describe MeToo "as the illusion of a movement." 89 The "legislative impotence" ${ }^{90}$ of MeToo is evocative of Medusa's lack of justice. U.S. President Donald Trump and Supreme Court Justice Brett Kavanaugh are still in power despite allegations against them, and Medusa is the only one in her myth that pays for Poseidon's actions. The myth of Medusa fits into this discourse very interestingly as both a cause and reaction. Not only is she considered a victim and survivor within the MeToo movement, but she is also re-imagined after the emergence of the concept of rape culture. Journalist Sasha Weiss proposes:

If sexual violence silences women in the moment, online spaces create the conditions under which that silence and its concurrent shame can be overturned because they are, at least ostensibly, safe. If one cannot call out their assailant in the darkness of a subway station for legitimate fear of physical violence, one can

\footnotetext{
${ }^{86}$ Sara Clarke-Vivier and Clio Stearns, "MeToo and the Problematic Valor of Truth: Sexual Violence, Consent, and Ambivalence in Public Pedagogy," Journal of Curriculum Theorizing 34, no. 3 (2019): 55.

${ }^{87}$ Clarke-Vivier, "MeToo," 56.

${ }^{88}$ Penn Bullock, "Transcript: Donald Trump's Taped Comments About Women," New York Times, October 8, 2016. https://www.nytimes.com/2016/10/08/us/donald-trump-tape-transcript.html.

${ }^{89}$ Clarke-Vivier, "MeToo," 67.

${ }^{90}$ Clarke-Vivier, "MeToo," 60.
} 
do so publicly on social media, backed by a chorus of women who have lived through the same. ${ }^{91}$

In saying so, Weiss supports the notion that sexual violence does indeed incite silence and fear in its victims. In other words, the phenomenon of turning to social media to voice sexual assault truths infers that the real world where sexual violence takes place provokes silence and fear in sexual assault victims. Medusa would be not only the victim of such crime, but also the voice and anger that women are afraid to display in real life. Medusa works alongside the MeToo movement by being the eyes that battle the male gaze for the MeToo survivors who may not want to be "seen"92 and may want to hide behind a hashtag.

The Time Magazine article "Silence Breakers" that names the primary speakers in the movement as their 2017 "Person of the Year", "insistently paints MeToo as a movement that transcends and even nullifies social boundaries." The diversity of women who have come forward during this movement sheds light on how, sadly, sexual assault and harassment in one form or another is akin to the female experience. While it might be too farfetched to say Medusa represents all women, her story is all the more powerful because she is representative of a large percentage of women who have experienced sexual violence in all its degrees. She stands up to the patriarchy which is very "trendy" in this age of female empowerment.

Considering MeToo narratives, Medusa's story expresses the emotional arc of a sexual assault victim. In addition to being the voice of the silenced, Medusa represents the accumulated rage of sexual violence victims. It is her rage that paints Medusa as the villain of the story-the stepping out of female stereotypes in such an (ironically) aggressive way, presents her as a rebel,

\footnotetext{
${ }^{91}$ Clarke-Vivier, "MeToo," 57.

92 Clarke-Vivier, "MeToo," 58.
} 
an insurgent, and an antagonist. May Sarton's “The Muse as Medusa” identifies with Medusa and thanks her for the "gift" of exploring the "frozen rage" that is within her — a "secret, selfenclosed and ravaged place." 93 Nonetheless, "Silence Breakers" suggests that the "emotional commonalities widely believed to be associated with experiencing sexual violence" include "a sense of shame, a desire to hide, anxiety about sexuality overall, fear of retribution, and fear of being identified solely with the experience of victimization."94

\section{1st Century Medusa: Why Billie Eilish?}

In conjunction with this essay, I photo-manipulated a portrait partly inspired by Medusa and partly inspired by Billie Eilish to be the cover images for a poetry collection on this very topic of Medusa and rape culture. I came to this conclusion when I asked myself: Who would Medusa be in the 21 st century? It would be easy to pull from popularized narratives, such as that of Hillary Clinton being the original and quintessential "nasty woman," to showcase contemporary women who have been "gorgonized." Clearly, a woman successfully gaining more and more authority, is one that scares and does not sexually stimulate certain men. Nonetheless, the first person that came to my mind was Billie Eilish.

Medusa challenges norms by being a female figure able to take down men - a woman that potentially could be more powerful than men. Medusa threatens the belief that men are superior to women. Accordingly, when Medusa showcases any sort of emotion that opposes prescriptive female stereotypes, such as being affectionate, cheerful, gentle, and being softspoken, ${ }^{95}$ she is attacked. Woolley agrees by noting that such violations of stereotypes deem

\footnotetext{
93 Bowers, "Medusa," 233.

${ }^{94}$ Stephanie, Zacharek, Eliana Dockterman, and Haley Sweetland Edwards, "TIME Person of the Year 2017: The Silence Breakers," Time, 2017. https://time.com/time-person-of-the-year-2017-silence-breakers/.

95 Alice Woolley and Elysa Darling, "Nasty Women and the Rule of Law," University of San Francisco Law Review 51, no. 3 (2017): 533.
} 
women as "less socially appealing," and will be "less liked and more personally derogated" compared to men with similar qualities. Any characterization that views a woman to be "the antithesis of the female nurturer" stereotypes her as a quintessential 'bitch. ${ }^{96}$

Billie Eilish is an intriguing addition to the Medusa discourse. Eilish does not conform to mainstream standards of femininity with her aesthetic and brand limited to loose and baggy clothing. The idea that "sex sells" does not merge with her brand, and that confounds everyone. She herself likes that baggy clothing maintains a veil of mystery about her, ${ }^{97}$ regardless of whether we as outsiders read that as something that stems from discomfort from being sexualized, an effort to maintain privacy, or a mere thrill of being mysterious. Nonetheless, the relationship between a celebrity and its watchers is one that almost feels like the watchers are promised the ability to see. Eilish's desire to hide her body only increases curiosity, which becomes problematic since Eilish, until recently, was underage. Still, underage girls are not protected from sexual harassment and assault, as the popular Instagram and Facebook page "Catcalls of New York" $"$ often showcases the stories of underage girls being the victims of scary and graphically lewd catcalls.

Beyond Eilish's unintended but inherent positioning in the discourse of sexual harassment, her work shows parallels and ironic twists with the Medusa myth. Her most famous song, "Bad Guy," talks about a woman who takes on the role of the "bad guy" since the guy in this situation will not take responsibility for his actions. If this reading is too subjective, another reading would be that the woman in the song simply leans into being the "bad guy" and lists why she would be viewed as the "bad guy": "I'm that bad type / Make your mama sad type / Make

\footnotetext{
${ }^{96}$ Woolley, "Nasty Women," 534.

${ }^{97}$ De Elizabeth, "Billie Eilish Reveals the Reason for Her Baggy Clothes in New Calvin Klein Ad." Teen Vogue, May 11, 2019, https://www.teenvogue.com/story/billie-eilish-baggy-clothes-calvin-klein.

98 Sophie Sandberg, "Catcalls of NYC," Catcalls of NYC. https://www.catcallsofnyc.com.
} 
your girlfriend mad type / Might seduce your dad type." ${ }^{99}$ The photo-manipulated images I created pull from both "Bad Guy" - which is the title of the photo series "The Might-SeduceYour-Dad-Type" - and her "When The Party's Over" music video. From said music video I pulled an image of Billie Eilish where black liquid spouting from her eyes has covered her face and combined it with an image of Medusa where her tears have blended with the blood from her decapitated head. ${ }^{100}$ I chose this version of Eilish as the emotional anchor of this painting to explore how Medusa's sexual assault and vulnerable moments have been overlooked by society. The dichotomy of the grotesque, monstrous, yet melancholic image of Eilish from "When The Party's Over" with the narcissistic, somewhat self-absorbed title of "The Might-Seduce-YourDad Type" is an homage not only to Eilish and her work, but also to the complexities of Medusa's symbolism. How is this eerie version of Billie Eilish the same Billie Eilish that could quote-unquote seduce your dad? Along with this sentiment of seducing someone's dad, it insinuates the subject to be a daughter figure, and the questions of young adult fetishization is unavoidable. The repetition of the line "I could lie, say I like it like that, like it like that" in one of the images is a line from "When The Party's Over"; I am using it to refer to the precarious topic of consent. The snakes in these images tie Billie Eilish and Medusa together, and the black liquid pouring from Eilish's eyes is my way of toying with the idea of sight and of seeing - a prominent theme in the Medusa myth.

\section{Conclusion}

\footnotetext{
99 Billie Eilish, “Bad Guy,” Darkroom Interscope Records, March 29, 2019.

100 Tavena Mejdouli, Medusa, print, Etsy, https://www.etsy.com/listing/737652390/medusa-prints. Original artwork of Medusa taken from Tavena Mejdouli (TavenaMegArt on Etsy) with permission.
} 
Medusa's journey in Western culture is a journey "from the mutilation and destruction of the female body in Greco-Roman myth to the celebration of the whole female self."101 Medusa's emotional arc as a sexual assault victim makes her "a fantasy wonder woman, a gift for those in need of emotional liberation." 102 While her story is not the all-important narrative of how to end sexual violence, Medusa is not just a cautionary tale of the power of women. Medusa fills the gap between fear and fury. She is unapologetically powerful, and she is undoubtedly relevant. Medusa and MeToo teach that "truth only gets people so far and that some realms of power are so entrenched that truth cannot begin to bend them." 103 As discussed, the rewriting and reclaiming of the Medusa myth by women parallels if not contributes to the success of female empowerment, and the myth itself is emblematic of the importance and impact of female voices and shows the potentiality of women who fight and "look" back. As the French philosopher and poet Hélène Cixous reiterates, "Women must write through their bodies, they must invent the impregnable language that will wreck partitions, classes, and rhetorics, regulations and codes, they must submerge, cut through, get beyond the ultimate reserve-discourse, including the one that laughs at the very idea of pronouncing the word 'silence,' the one that, aiming for the impossible, stops short before the word 'impossible' and writes it as 'the end."'104

\section{Poetry Explained}

Included is a series of poems, samples of my larger collection, narrating a potential origin story in which Poseidon rapes Medusa, and Athena, out of guilt and solidarity, transforms Medusa into the gorgon that she is known as today. Poem "I. Prelude" explores the current

\footnotetext{
101 Bowers, "Medusa," 235.

102 Silverman, "Medusa," 124.

103 Clarke-Vivier, "MeToo," 71.

104 Hélène Cixous, "The Laugh of the Medusa," Signs 1, no. 4 (Summer 1976): 886.
} 
landscape of rape culture. Poem "II. The Setting Sun” explores sexual assault and harassment. Poem "III. Hatching", while short, is an important transitional moment post-assault. It is a liminal poem that touches the self-imposed guilt that some sexual assault victims feel, and the anger and dissatisfaction with rape culture that parallels Medusa's transformation from victim to aggressor. Poem "IV. The Statue Garden" handles the emotional baggage that comes with sexual assault - primarily the experiences with depression. Lastly, "V. The Way They Won’t Remember You" is a conclusion poem that stands on its own. The imagery in this poem comes from Matt Rhodes' illustration of Medusa's last moments, shown in the perspective of her being the one who is vulnerable and hunted. ${ }^{105}$

The choice to focus on depression as primary emotional baggage may seem confusing to some, as it does not typically correspond with the anger of Medusa and the MeToo movement. However, I creatively felt more attracted to the fear and silence that the Time Magazine article "Silence Breakers" referred to. Additionally, a study found that rape survivors have a high risk of developing major depression and generalized anxiety disorder. ${ }^{106}$ A 1993 study also found a correlation not only between suicide attempters and histories of sexual assault, but also that "female suicide attempters [with] a history of sexual abuse are disproportionately vulnerable to repeated suicidal behavior." 107 Poem "Day 52 on Escitalopram Oxalate, (1) 10 mg tab" serves an example of this theme in my work; it is about the drug Escitalopram Oxalate which is the technical term for the commonly used antidepressant, Lexapro.

${ }^{105}$ Matt Rhodes, Medusa, Illustration with Tumblr Commentary, Reddit, 2015. https://www.reddit.com/r/SympatheticMonsters/comments/9bt67c/medusa_by_matt_rhodes/.

106 Amy L Brown, Maria Testa, and Terri L. Messman-Moore, "Psychological Consequences of Sexual Victimization Resulting from Force, Incapacitation, Or Verbal Coercion," Violence Against Women 15, no. 8 (June 2009): 898-919, https://doi.org/10.1177/1077801209335491.

${ }^{107}$ M. van Egmond, N. Garnefski, D. Jonker, and A. Kerkhof, "The Relationship between Sexual Abuse and Female Suicidal Behavior," Crisis: The Journal of Crisis Intervention and Suicide Prevention 14, no. 3 (1993): 129-139, https://www.ncbi.nlm.nih.gov/pubmed/8281805. 
The poems "I Wish Billie Eilish Could Stay 17" and "I Saw Her Tits!: The Twitterverse" are the feeble connection between the collection and its accompanying photoshopped images. "I Wish Billie Eilish Could Stay 17" references the song "Sixteen Going On Seventeen" from the musical The Sound of Music so that the lyrics can be brought out of its original context and its tone altered. What was once a cute show tune between two young lovers has in this context turned into an eerie warning for young women approaching womanhood. This warning felt fitting for someone like Billie Eilish — a singer/songwriter whose age had faintly protected her from the lewd comments that her stardom and femininity attracted. However, the quick transition from seventeen to eighteen, from being a minor to being of legal age, somehow "allows" these comments to be publicized since it seems less inappropriate than when she was seventeen. That lead to the poem "I Saw Her Tits!: The Twitterverse." This poem is a collection of Twitter tweets on a thread regarding an image of Billie Eilish in a tank top. ${ }^{108}$ On the one hand, some tweets reprimand the vulgar and suggestive comments that this image garnered, especially because Billie Eilish, while being a very famous celebrity, was underaged. On the other hand, some Twitter and Instagram comments criticize Eilish for sexualizing herself with song lyrics such as "bruises on both my knees for you"/"might-seduce-your-dad-type"109 and Instagram captions such as "comment ur dick size."

\footnotetext{
108 “Billie Eilish Twitter Thread," Twitter, June 23, 2019, https://witter.com/pogbaescobar/status/1142913814482116608?lang=en.

109 Billie Eilish, "Bad Guy."
} 
The Interdependent: Journal of Undergraduate Research in Global Studies

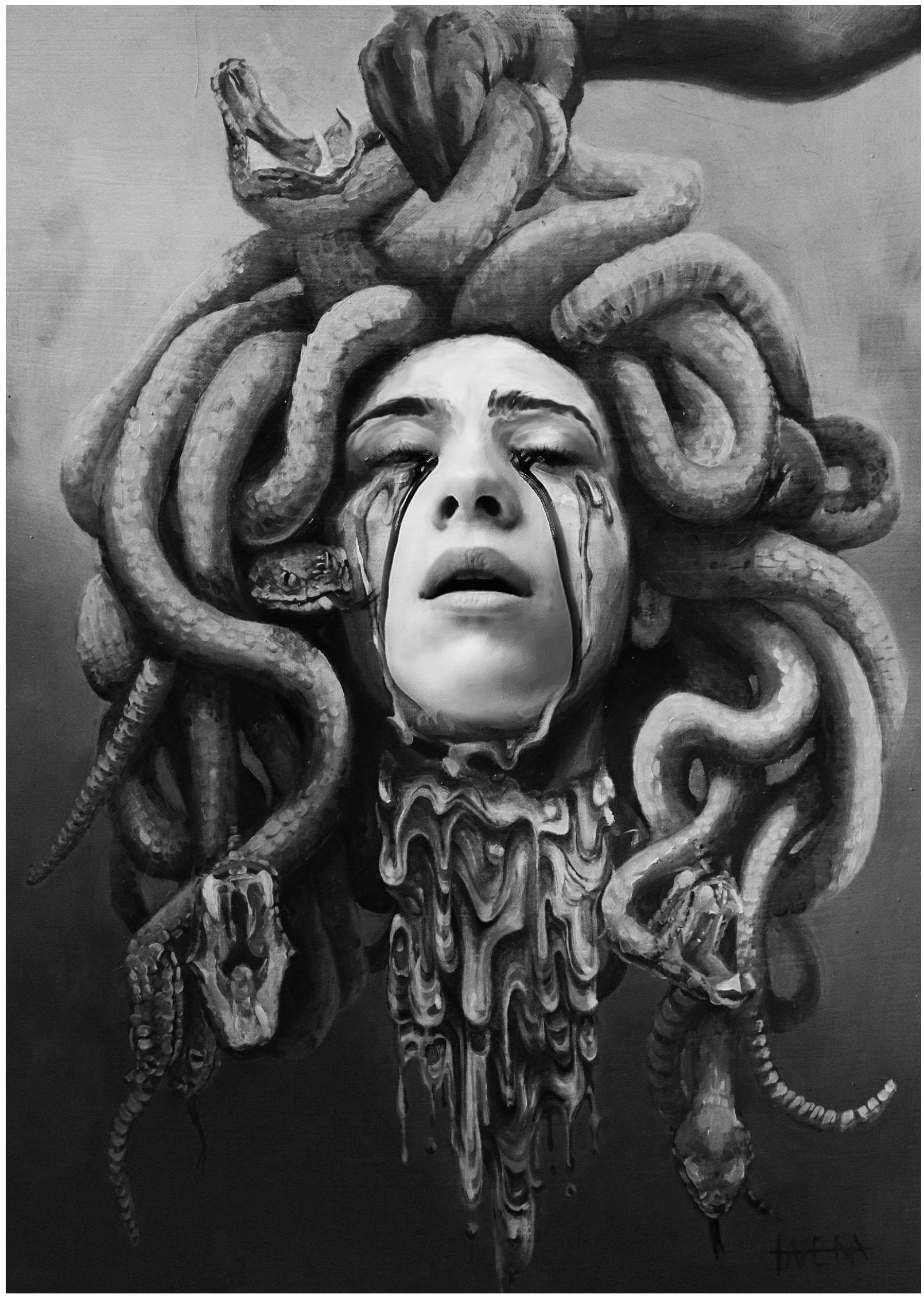




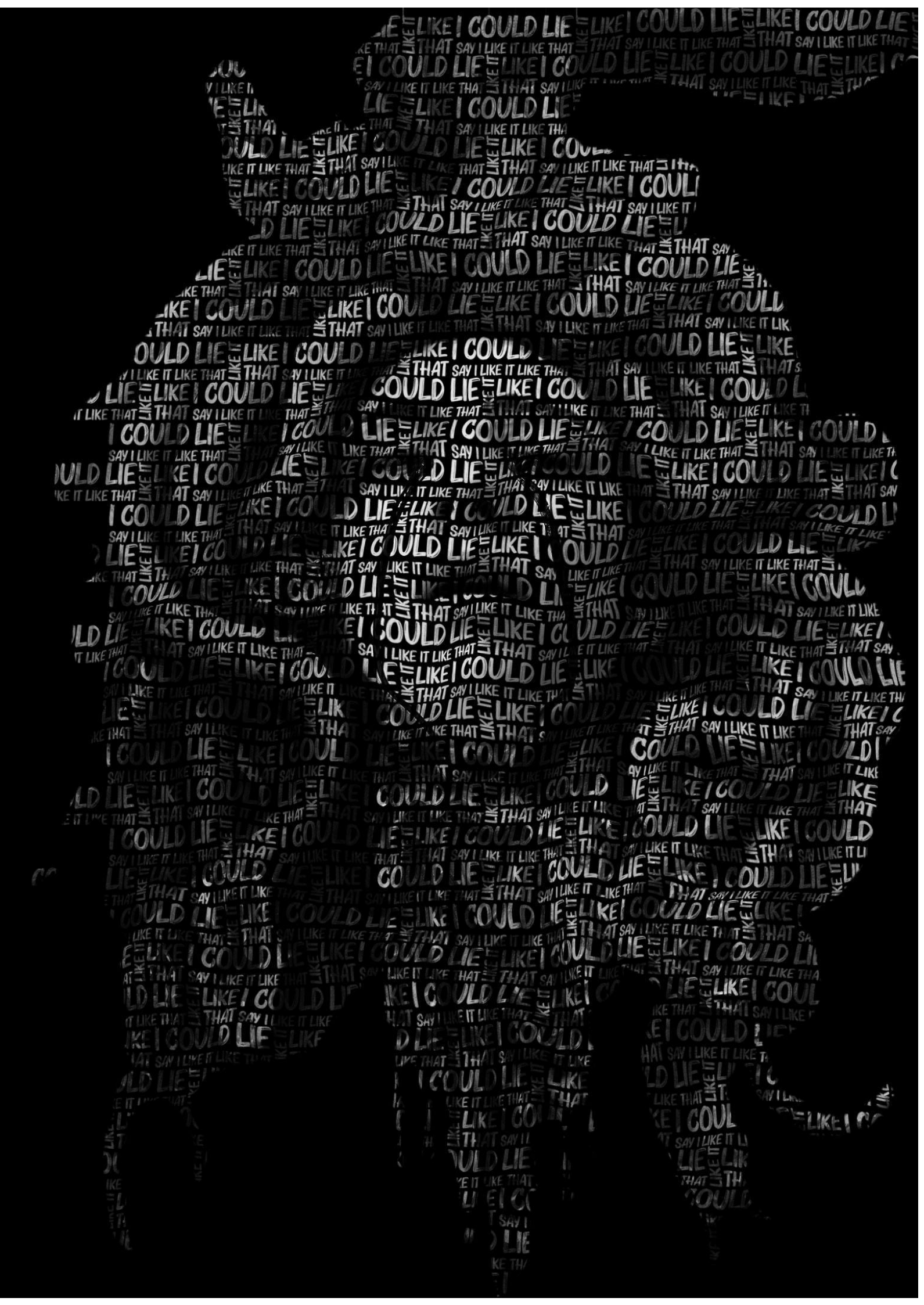




\section{The Prelude}

Nobody remembers the beauty before the beast.

Mesmerizing locks before snakes;

waves of molten gold only Aphrodite

could have allowed another.

Suitors who dare

can't help but catch their breath

at her nymph-like allure. Oh, lustful oblivion,

how to take a step across her godly barrier?

Medusa!

Medusa's tresses have me weak!

Down her back

around her shoulders

like a shield,

it's her hair itself

that draws the suitors, it's her hair

that makes men stutter, it's her hair, that catches the attention of

Poseidon. 


\section{Wish Billie Eilish Could Stay 17}

You are sixteen going on seventeen

Baby, it's time to think

Better beware, be canny and careful

Baby, you're on the brink

You are sixteen going on seventeen

Fellows will fall in line

Eager young lads and rogues and cads

Will offer you food and wine

Totally unprepared are you

To face a world of men

Timid and shy and scared are you

Of things beyond your ken

- The Sound of Music (1965)

You are seventeen going on eighteen

Billie, it's time to think

Better beware, be canny and careful

Billie, you're on the brink

You are seventeen going on eighteen

Fellows have prepared their eyes

Eager lads with judgements gone lapse

Will fall over themselves to take a peek

Totally prepared are you

To face a world of men

Fuck timid and shy and scared are you

Of things you can't fully understand 


\section{Saw Her Tits!: The Twitterverse}
she THICK
bruises on both my knees for you
might-seduce-your-dad type
comment ur dick size
*
not a minor
but i'm the one sexualizing her?

apparently I'm not allowed to think she's attractive until

few months from now

she's legal now

she wears baggy clothes so

people won't comment on her body but the mINUTE

she wears a tank top y'all come @ her.

It's like 10x worse in the fact

that this photo is old and from

when she was 14 YEARS

If she hadn't said and posted all

those things then you would've been in the wrong. 


\section{The Setting Sun}

Left cheek pressing against cool white marble, Athena's temple, Medusa stretches her neck upwards.

Run away from the pressure of his body. His grip at the base of your neck.

His breath. No, not his eyes.

Don't look for help in his eyes; they give no mercy.

Gives no mercy, no mercy.

You hear the stories.

But you never think

it's going to happen to you.

Still squirming but quickly losing heart, Medusa tries calling out as Poseidon pushes into her, the echoes of her voice mocking her

Even the setting sun whispers goodbye through the columns.

She wants to go with it.

The blinding sun hides behind the horizon and Medusa tilts her head up, feeling herself emptying.

Be nothing so he can take nothing.

A current of anger from womb to windpipe.

He will never be remembered for all his deeds.

Friezes etched with Athena,

Medusa hopes with a silent wail:

Maybe she can help me.

Athena, please, you're the only one that can

make it stop- 


\section{Hatching}

Run away from the pressure of his body.

His grip at the base of your neck.

His breath. No, not his eyes.

Don't look for help in his eyes;

it gives no mercy,

no mercy, no mercy.

His eyes,

his eyes,

whatever it takes,

turn his eyes.

Anger flares through Athena

as she witnesses Poseidon's plundering.

The desecration; the disrespect.

But her vow! Her vow!

So promiscuous, so immoral.

Athena turns away,

Hiding chaste eyes behind her aegis.

After a thick moment, Athena slowly peeked,

Poseidon disappeared like a breeze,

Medusa left whimpering,

her pale body growing cold.

Eyes still clenched tight.

Turn their eyes,

turn their eyes,

whatever it takes,

please, Athena,

please turn their eyes.

Medusa, my faithful,

I will make them pay.

I will cut your aurous mane

off at the roots and snakes will grow

and grow. Don't be afraid

if they look and they stare.

Lust will turn to fear,

and in fear they shall stay

Forever. 


\section{God as My Witness}

apparently God is not enough

to keep fear from blaring and words from exiting mouths

$\mathrm{He}$ is and He should be

but a woman can't walk out of a church

and feel as safe as she did while in it

women walk wearing faces

they're told need smiles

hoping he wasn't talking to about them

holding their breaths for as long as it takes for him to stop looking

i suffocate

in the span of time it takes to feel clean again

i can't be a woman without also being a victim

waiting to happen

but there is no

clean

no cleanliness for women who have been labeled and predicted

and are waiting for harassment and assault

since it's bound to happen

no woman goes unscathed

because she need only walk down the street to feel unsafe

need only become victim to a passing glance

to worry about

thoughts God can't stop

intentions God can't help hear

free will God loved us enough to give to us

to perhaps become a victim again

So no

God is not enough

when $\mathrm{He}$ is ignored

by those who think $\mathrm{He}$ is

not witnessing

and $i$ wonder who else is left

to cling onto because

God is not enough for mothers

who cannot hug their children

not enough for women not wanting children

in case it's a girl 
in case it's a boy

God

will you hate me

if $i$ look for the wisdom you told me not to trust

if $i$ beg Athena to protect me the way she did Medusa

Father

you loved us so much you tried to keep us naive

but fists still clench at my heart

and i still feel fear whenever they look at me

God, tell them to stop

Athena, please make them stop

so i'll cut it off at its roots

hoping snakes grow

and my skin shed

and i'll do it all wrong

i'll molt into something they won't want to look at

remove my desirability until i am the stone

and they are the monster 


\section{The Statue Garden}

Far beyond, through hidden tracks, through rocks bristling from shaggy trees, in the fields and along the paths, is a refuge from the heavens and the earth.

Statues with pained faces, sad faces, panic-stricken eyes.

Medusa thinks about her statue garden and the fear that lingered through the grounds. Flowers grew around the feet of forgotten men, vines around their legs and torsos.

They seem to all forget the days they were eyeing her with the desire to ravish rather than the desire to kill.

Or rather, eyeing her and surviving the experience.

Medusa clenches her teeth, bulging her jaw muscles.

She takes a closer step towards the three men

Bodies grey and unmoving.

Almost expecting their eyes to move with her, Medusa encircles the statues, not daring to touch the men as if they could still burst through their crusts and touch her.

She flinches, taking a step back.

Nobody will ever touch her again

and yet she is still afraid

of the now inanimate things

that can not touch her, still afraid of those hands that are stuck reaching out to plead her, still afraid of the mouths that traveled without bounds.

They died fearing her and yet she is still afraid. 


\section{Day 52 on Escitalopram Oxalate, (1) $10 \mathrm{mg}$ tab}

i throw my underwear on the floor

and is ready to get it over with

my body tells me yes $i$ think

and he knows it too

he asks me what $i$ want

and i tell him i don't know

he holds me as i cry

kissing sorry's into my hair

it's in the peeling

not the nakedness

that makes me hesitate

the step by step

the asking

the needing to give an answer

say yes

I love you

i love to love you

but i don't feel love during sex

what does that feel like

we stop having sex

and five days feel like an era

i finally believe in no's

to keep saying no

until yes starts to feel wrong

so he kisses every inch of my body

calming every insecurity i didn't know i had

he speaks into my nothingness and tells me

he loves me for me and finally

i don't feel like i need to sell myself 


\section{The Way They Won't Remember You}

Is this it?

Is this how it ends?

Facing the darkness with the light behind me,

Thundering rain, and hissing snakes,

Just kill him...

You'll be fine....

... You'll die

He is nothing...
... Athena is his half-sister
Athena gave you powers...

... She also gave him her mirror shield

Perseus stands like a meaty wishbone,

hungry to gain his glory.

I bite. I cry. I clench. I turn.

I come out of the shadows,

my last taste of rain,

I come to face the face of one, the eyes of thousands.

Look, look, why don't you?

Look at me in all MY glory.

I will never stop fighting.

When the idea in your head

I will never stop fighting.

and the mirage in the reflection

I will never stop fighting.

and the gorgon in their eyes

I will never stop fighting.

don't match up,

I will never stop fighting.

Look!

don't match up,

who's right?

Look!

who's right?

Look!

who's right?

I looked. 


\section{Acknowledgments}

This article is a revised excerpt of my senior thesis and does not reflect the full scope of my work. Nonetheless, I would like to thank my senior advisor, Professor Timothy Tomlinson, for his guidance during a pandemic in both the written and creative aspects of my thesis, and for always standing up for my work. I would also like to thank Victor Galov for his support throughout the writing process, and Tavena Mejdouli for allowing me to use and manipulate her art for my own creative work. This article would not exist without these people, my anonymous editor at The Interdependent, and everyone in Global Liberal Studies. 